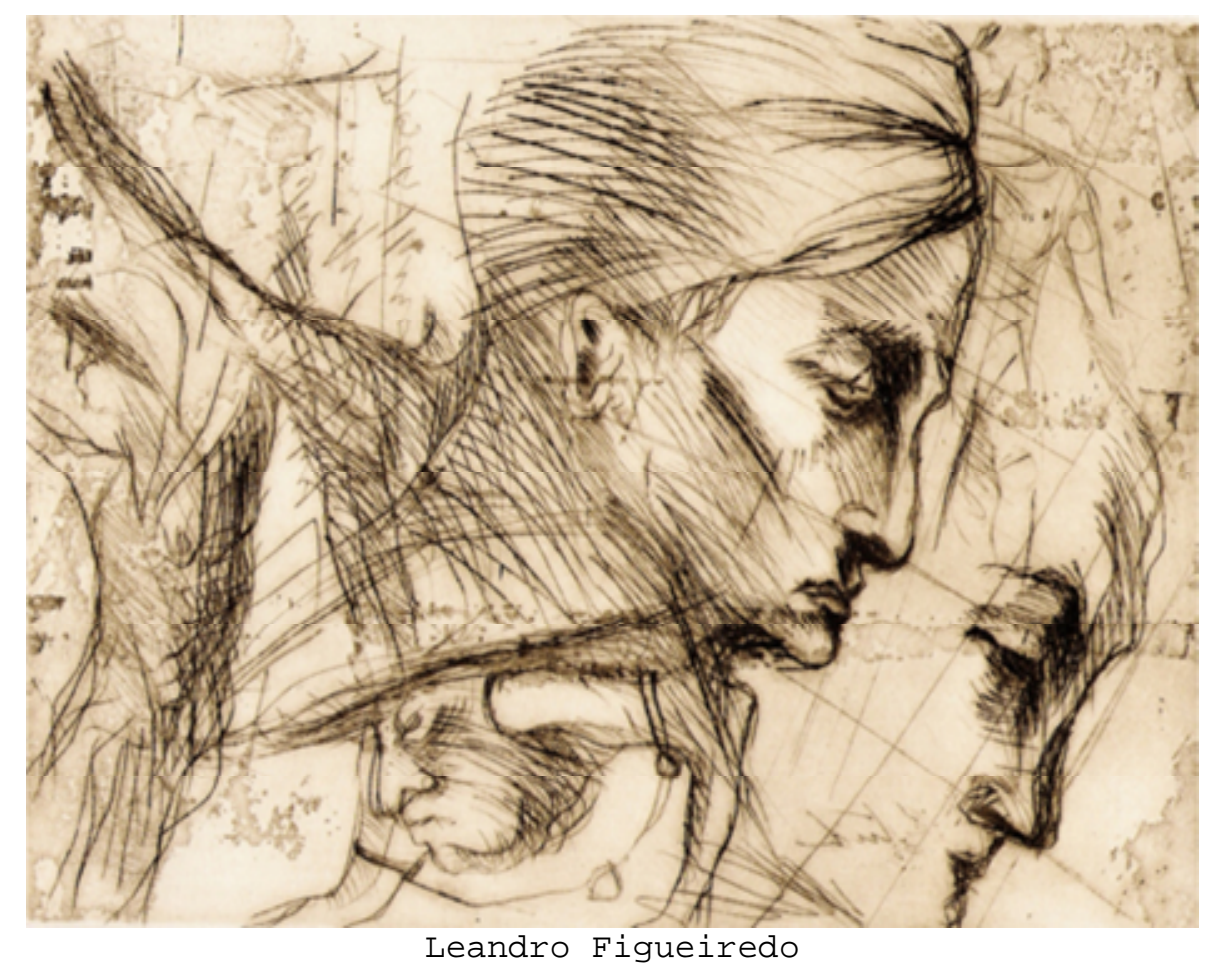

\title{
Leitura e memória na cibercultura
}

Como procurei demonstrar, somente o impossível pode acontecer. Jacques Derrida

\section{Maria Antonieta Pereira}

Coordenadora Geral do Programa A tela e o texto.

\section{Resumo}

Este artigo apresenta um breve histórico do Programa de Ensino, Pesquisa e Extensão A tela e o texto, nos seus 10 anos de existência, período em que atuou na formação de leitores e educadores. Associando algumas teorias de rede, especialmente os conceitos de hipertexto e rizoma, à desconstrução derridiana, o Programa estabeleceu um vigoroso desejo de saber-fazer. Como resultado disso, seus membros têm desenvolvido atividades junto às populações com alto nível de exclusão social e cultural e junto aos mais diversos tipos de educadores. Os dados daí decorrentes alimentam projetos de pesquisa aplicada. 
Palavras-chave: hipertexto, rizoma, desconstrução, pesquisa aplicada.

- Programa de Ensino, Pesquisa e Extensão A tela e o texto nasceu em 1998, como um grupo de Iniciação Científica que analisava as relações entre Brasil e Argentina a partir de textos (especialmente os literários) e telas (especialmente as cinematográficas). Desde seu começo, esse grupo tentava articular 2 linhas de pesquisa ("Literatura, História e Memória Cultural" e "Literatura e Outros Sistemas Semióticos"). Essas possibilidades já vinham sendo desenvolvidas em minha pesquisa de doutorado, finalizada em 1997, quando analisei o romance $A$ cidade ausente, de Ricardo Piglia, a partir da idéia de hipertexto desenvolvida por Pierre Lévy.

Além de conquistar prêmios na VIII Semana de Iniciação Científica da UFMG, esse grupo também desenvolveu atividades de extensão em cidades da Grande $\mathrm{BH}$ e editou um Caderno Virtual (1) com resultados de suas reflexões e ações. Logo a seguir, outros dois grupos de Iniciação Científica foram formados: um deles pesquisou o tema "Literatura e crítica estudos contemporâneos", onde se discutiam as relações entre educação e literatura(2), e o outro estudou "O sujeito contemporâneo: um olhar literário"(3), debatendo a subjetividade desenhada pelas produções em rede. Esse breve histórico mostra que, tendo começado com um vigoroso desejo de saber-fazer, o Programa dedicou-se a discutir certas teorias do conhecimento que o levaram à pesquisa aplicada. Construindo mecanismos de produção coletiva de conhecimento, o Programa passou a funcionar como um laboratório de experimentos discursivos e pragmáticos que desautomatizou as relações formais entre discentes/docente. A partir daí, as tarefas, as alegrias, as frustrações e os saberes advindos das incontáveis tentativas de formar leitores e educadores foram sendo construídos e criticados, desconstruídos e re-formatados, experimentados e avaliados até se chegar a alguns projetos consolidados, a algumas propostas bem definidas e a determinadas premissas teóricas. Contudo, embora tenha criado certas tecnologias intelectuais que lhe garantem perspectivas de longo prazo, o Programa conseguiu manter a postura crítica que preside os começos. Às suas certezas, continua mesclando atitudes de estranhamento da realidade e a necessária indignação frente às misérias humanas e, por isso, prossegue se rebelando contra o lugar comum e optando por buscar alternativas para problemas que parecem não ter solução.

Hoje, o Programa abriga dezenas de projetos dedicados à formação de leitores e educadores contemporâneos. Por sua trajetória nessas áreas, foi ganhador, em 2007, do maior prêmio brasileiro de fomento à leitura, o VIVALEITURA, 
patrocinado por MINC, MEC, OEI e Fundação Santillana. Acreditando na potência da idéia de hipertexto, o pequeno núcleo inicial de pesquisa desenvolveu ações e reflexões voltadas para o ensino e a extensão. A análise crítica das teorias contemporâneas de leitura - cujo principal atributo, nos vários campos do saber, é serem teorias de rede - (4)foi mostrando que, para se ler o texto impresso, era preciso também ler as imagens, preferencialmente aquelas que se movimentavam nas telas do cinema, da televisão, do computador e do celular. Além disso, esse grupo logo percebeu que as trocas culturais entre telas e textos - fossem elas realizadas nas fronteiras de diferentes línguas/países ou fossem efetivadas por diversos meios/linguagens - eram sempre assimétricas e conflituosas. Essa desarmonia contribuía para se pensar as obras de arte, especialmente aquelas produzidas por palavras e imagens, como um território aberto, passível de freqüentes renovações, e não-totalizável.

Tais investigações se desdobraram em dezenas de monografias, teses, dissertações, artigos científicos, livros, revistas eletrônicas e impressas, alfabetizações, capacitações, oficinas, cursos, pesquisas de pós-doutorado, bibliotecas comunitárias, mostras de cinema e vídeo, projetos de leitura nos ônibus e no metrô, ações ecológicas, contação de estórias, edição de livros de baixo custo, programas de rádio e TV, fóruns de ensino de leitura, assessorias, conferências e pesquisas em universidades de Argentina, Peru, Chile e Canadá.

Certamente a composição diversificada do grupo A tela e o texto constituiu-se como uma das mais fortes características do Programa, transformando-o num espaço de leituras em rede, em que as teorias funcionavam como exercícios intelectuais de provocação do saber e de comportamentos democráticos, transformando, paulatinamente, os objetos de pesquisa em instrumentos de intervenção social. Esses espaços de compartilhamento de estudos e práticas, não raras vezes, levaram a profundas divergências e rupturas internas, especialmente quando estavam em jogo certos aspectos relativos ao papel do intelectual na sociedade contemporânea.

Nesse caso, podemos verificar que o modelo de produção de conhecimento do qual dispomos estimula atitudes e competências típicas de sociedades que, cada vez mais, foram se organizando a partir da apropriação individual do saber. Uma das características mais importantes desse sujeito do conhecimento é seu individualismo, espaço em que a inteligência é considerada um bem pessoal, cujas aquisição e utilização devem, em primeiro lugar, trazer benefícios a seu proprietário. 0 conhecimento tem, nesse caso, uma dimensão técnico-pragmática de servir aos próprios interesses de quem o manipula. Nessas circunstâncias, o papel das disciplinas é decisivo, pois elas 
parecem permitir o recorte do conhecimento em partes passíveis de serem dominadas por um indivíduo.

Contudo, numa perspectiva de inteligência coletiva (5) (conceito desenvolvido por Pierre Lévy), a situação se modifica amplamente, pois as iniciativas de produção de saber e de sentido passam a ser estratégias compartilhadas e, por isso mesmo, reorientadas com freqüência já que, para sua existência, concorrem diferentes pontos de vista. Nesse caso, não há o desaparecimento das disciplinas ou das competências individuais mas a criação de novas possibilidades de cruzamento dos saberes sob a forma de transdisciplinas que ampliam os espaços formais de aprendizagem para além da sala de aula tradicional. No caso do Programa A tela e o texto, essa inteligência coletiva foi amplamente desenvolvida a partir de três mecanismos principais: 1) a forma de organização do grupo (conjugação de estruturas rizomáticas e arborescentes); 2) a combinação de protagonismo individual e instâncias de compartilhamento; 3) a associação entre trabalho voluntário e esporádicas atividades remuneradas.

Evidentemente, todo esse movimento teórico-pragmático seria impossível, se não houvesse uma perspectiva desconstrutora no interior do Programa A tela e o texto, cuja rede interna (base teórica, formas de organização, instâncias deliberativas e executivas) está diretamente articulada às redes externas (parceiros, instituições governamentais, comunidades, escolas etc.) com as quais constrói propostas de formação de leitores e educadores. Nesse sentido, o Programa busca considerar uma das mais importantes proposições derridianas, a partir da qual o interior e o exterior não constituem uma oposição binária, simples e excludente mas compõem interações complexas e mutuamente implicadas. Segundo Derrida, na cultura metafísica ocidental, houve o estabelecimento de oposições fortes tais como escritura boa/escritura má, natureza/artifício, humano/divino, alma/corpo, consciência/paixões, livro total/texto. Todas essas oposições constroem modelos de pensamento e vida cuja base é o confronto dialético entre as idéias de dentro/fora, as quais foram desenvolvidas ao longo da própria história da metafísica, associando os conceitos de logos e phoné. Analisando, nesse caso, as proposições aristotélicas, Derrida mostra como

A voz, produtora dos primeiros símbolos, tem com a alma uma relação de proximidade essencial e imediata. Produtora do primeiro significante, ela não é um mero significante entre outros. Ela significa o "estado de alma" que, por sua vez, reflete ou reflexiona as coisas por semelhança natural. Entre o ser e a alma, as coisas e as afecções, haveria uma relação de tradução ou significação natural; entre a alma e o logos, uma relação de simbolização convencional. E a primeira convenção, a que se referiria imediatamente à ordem da significação natural e universal, produzir-se-ia como linguagem falada. A linguagem 
escrita fixaria convenções, que ligariam entre si outras convenções. (6)

Ao estabelecer o privilégio da phoné, essa forma de pensar o mundo e os homens desenvolve uma concepção de linguagem falada como aquela que, por estar perto da alma, também está perto do sentido ou da verdade e, por isso, constitui a primeira convenção. A linguagem escrita passa a figurar como uma linguagem secundária, como uma derivação técnica da primeira, padecendo da ausência de um sentido que a constitua. Nessa perspectiva, constroem-se pares fortemente opositivos cuja relação agonística acaba construindo a hegemonia de um em relação ao outro. Um processo dessa natureza, que tende a reduzir todas as diferenças a semelhanças, também provoca situações permanentes de exclusão, intolerância e critérios rígidos de verdade, instrumentos perfeitamente adequados para alimentar todas as formas de violência. Gerando assimilações e totalidades, a metafísica ocidental também gerou (e tem gerado) a violência colonizadora, os autoritarismos e as mais refinadas formas de abuso, exclusão, genocídios e crimes contra os viventes.

Ao trabalhar com a proposta derridiana da desconstrução de certos discursos sobre o leitor e o educador, e também com as teorias de rede (especialmente as idéias de rizoma, hipertexto e inteligência coletiva), o Programa $A$ tela e o texto desenvolveu outras formas de se pensar a leitura e a produção de textos na sociedade contemporânea. Considerando tais processos como algo que extrapola as habilidades e competências necessárias ao uso de textos impressos, passamos a dialogar com as novas subjetividades produzidas pela cibercultura e por uma perspectiva ecológica, planetária, cósmica. A partir de sua estrutura e seus propósitos, o Programa se articula como uma rede cujos links são configurados internamente, mas a partir de demandas externas que vão modificando seu perfil, sua composição, seus projetos e seus objetivos de curto e longo prazos. Em constante debate com as comunidades universitárias e periféricas, com a sociedade globalizada e analfabeta, com as telas e os textos, nossos projetos modificam-se e modificam essa rede de interlocutores, criando verdadeiros fóruns de debate, de deliberação e ação educativas.

Após 10 anos de existência, é ainda em Derrida que o Programa busca a compreensão dos fenômenos sociotécnicos que presidem a formação de leitores, dentre os quais se destaca o papel do professor (7) - aquele que é capaz de professar, ou seja, "de declarar [algo] publicamente". Por causa dessa declaração que é pessoal e pública, cognitiva e afetiva, estética e ética - o professor estabelece um compromisso, empenha sua palavra. "Professar é se comprometer declarando-se, fazendo-se passar por, prometendo ser isso ou aquilo." Para nós, do Programa, o 
mais importante "é essa promessa, esse compromisso de responsabilidade" que, sendo um ato de fala e de ficção, é contudo também uma performance, uma atuação em redes sociotécnicas, um experimento de inteligência coletiva. No âmbito do Programa, até o estudante, que em geral não é considerado um trabalhador, põe-se a trabalhar, sustentando com seu entusiasmo e seu verdor teórico-prático os grandes projetos de leitura que hoje desenvolvemos em espaços que vão do local ao internacional.

Considerando o "direito incondicional de colocar questões críticas" (8), os 10 anos que hoje comemoramos buscam fortalecer uma "Universidade sem condição" (um espaço crítico de resistência e metamorfose) que desenvolva "o direito de princípio de dizer tudo, ainda que a título de ficção e de experimentação do saber, e o direito de dizê-lo publicamente, de publicá-lo" (9). Nessa universidade e nesta Faculdade (que ainda são porvir mas também já são passado que passa neste presente), procuramos desenvolver os processos de ensinoaprendizagem com base no "como se" da literatura, "dessa instituição democrática que se chama literatura, ou ficção literária" (10), visando ao questionamento dos conceitos de homem, humanidade e Humanidades. Tendo em vista que a disposição teórica precisa se desdobrar em "um penhor, um compromisso, uma promessa, um ato de fé, uma declaração de fé, uma profissão de fé", o Programa cultiva as possibilidades performativas de um discurso que produz os acontecimentos aos quais se refere.

Derrida apresenta 7 teses - ou profissões de fé - a partir das quais seria factível pensar numa nova humanidade. Sendo impossível comentá-las todas aqui, tomaremos como objeto de reflexão apenas a quarta tese, tendo em vista sua importância para os 10 anos do Programa. Nessa quarta profissão de fé, Derrida assinala os vínculos da literatura "com a ficção e a força performativa do 'como se' ", além de "sua ligação com o direito de dizer tudo (ou de não dizer tudo) que funda tanto a democracia quanto a idéia de soberania incondicional" (11). Por outro lado, como não poderia deixar de ser, o autor relativiza a própria idéia do "como se" acrescentando-lhe as infinitas possibilidades de um "talvez" que alteraria as fronteiras da própria universidade pois atuaria ao mesmo tempo em seu fora e seu dentro, na linha estreita e porosa de seus limites:

Pensar isso não é uma operação acadêmica, especulativa ou teórica. Nem uma utopia neutra. Do mesmo modo que o dizer não é uma simples enunciação. É sobre esse limite sempre divisível, é nele que o que acontece acontece. É ele que é afetado e muda. É ele que, por ser divisível, tem uma história. Esse limite do impossível, do "talvez" e do "se", eis o lugar em que a Universidade divisível se expõe à realidade, às forças do fora (quer sejam culturais, ideológicas, políticas, econômicas ou outras). É aí que a Universidade está no 
mundo que ela procura pensar. Nessa fronteira, ela deve, portanto, negociar e organizar sua resistência. E assumir suas responsabilidades. (12)

Negociando nossa resistência e assumindo nossa
responsabilidade, neste momento de celebração e alegria,
renovamos nosso compromisso com os milhões de brasileiros
excluídos da leitura, da escrita, do cinema, da TV de
qualidade, da literatura, do mundo digital. Renovamos,
portanto, nossa condição de professar, nossa profissão de
professor, nossa profissão de fé. Parafraseando Derrida,
poderíamos dizer: vamos com calma. Mas nos apressemos. Porque
não sabemos exatamente o que nos aguarda.

\section{Resumen}

Este artículo presenta un breve histórico del Programa de Ensino, Pesquisa e extensão $A$ tela e o texto, en sus 10 años de existencia, período en que actuó en la formación de lectores y educadores. Asociando algunas teorías de red, especialmente los conceptos de hipertexto e rizoma, a ladeconstrucción derridiana, el Programa estableció un vigoroso deseo desaber-hacer. Como resultado de eso, sus miembros desarrollan actividades junto a las poblaciones con alto nivel de exclusión social y cultural y junto a los más diversos tipos de educadores. Los datos que desde ahí advienen alimentan proyectos de investigación aplicada.

Palabras-clave: hipertexto, rizoma, deconstrucción, investigación aplicada.

\section{Notas}

[1] Derrida retoma a discussão ética iniciada por Jeremy Bentham que, em 1789, publicou An Introduction to the Principles of Morals and Legislation, obra na qual, pela primeira vez, a filosofia defende claramente os interesses dos animais. Reivindicando ética e coerência com os princípios da igualdade e da dignidade - que definem o tratamento a ser dado aos humanos - Bentham afirma que o regime republicano deveria estender tais princípios a todos os animais.

[2] DERRIDA, 2002.p. 55.

[3] O especismo constitui a discriminação de outras espécies por parte dos humanos, visando atender apenas aos interesses da própria espécie. Cf. SINGER, 2002 .

[4] This book is about the tyranny of human over nonhuman animals. This tyranny has caused and today is still causing an amount of pain and suffering that can only be compared with that which resulted from the centuries of tyranny by with humans over black humans. The struggle against this tyranny is a struggle as important as any of the moral and social issues that have been fought over in recent years. Cf. SINGER, 3.ed. 2002 . p. $x x$.

[5] Derrida denuncia o uso do termo no singular - o Animal - como categoria reveladora de uma oposição tão forte entre humanos e não-humanos que transforma os últimos em uma massa amorfa, isenta de singularidades. Como resultado disso, o Animal constitui-se como um ser - melhor seria dizer, como um vivente - somente na medida em que se torna um objeto para os 
humanos, suprindo suas necessidades. Como sua singularidade não é reconhecida, também lhe negam interesses próprios e, portanto, direitos.

[6] DERRIDA, 2002.p. 34 .

\section{Referências bibliográficas}

CARTA DA TERRA. Disponível em:

www.mma.gov.br/estruturas/agenda21/arquivos/carta_terra.doc. Acesso em: $17 / 05 / 2009$.

DECLARAÇÃO UNIVERSAL DOS DIREITOS DOS ANIMAIS (UNESCO). Disponível em: http://www.apasfa.org/leis/declaracao.shtml. Acesso em: 17/05/2009.

DERRIDA, Jacques.

O animal que logo sou (a seguir). Trad. Fábio Landa. São Paulo: Ed. UNESP, 2002 .

SETOR VERDE. Programa de Ensino, Pesquisa e Extensão

A tela e o texto. Disponível em www.letras.ufmg.br/atelaeotexto. Acesso em: $17 / 05 / 2009$.

SINGER, Peter.

Animal Liberation. New York: HarperCollins Publishers Inc. 3. ed. 2002. 